\title{
New organization pledges scientific expertise for viral outbreaks
}

WASHINGTON, DC - The next time a viral outbreak like H1N1 influenza or the SARS virus threatens the world, Robert Gallo wants the scientific community to be ready. To make that happen, last month Gallo launched the Global Virus Network (GVN), an international group of leading virologists and medical researchers tasked with providing scientific expertise to government agencies in the face of emerging infectious viral agents.

"An independent voice of medical laboratory scientists would be a great addition to the surveillance world," says Gallo, who co-discovered the HIV retrovirus in 1984 and is currently director of the Institute of Human Virology at the University of Maryland School of Medicine in Baltimore.

At a meeting here in early March, representatives from 16 countries gathered to determine the network's mandate and mission. As envisioned by its members, the GVN will serve as a clearinghouse for rapid data collection and disease containment. In response to an outbreak, the organization would send researchers from one of its many international academic centers into the field to collect samples and help local officials diagnose and treat infected people.

The GVN, which hopes to secure a budget of at least \$25 million per year with donations from governments, research centers, charitable organizations and private companies, would engage with-yet remain autonomous of-other

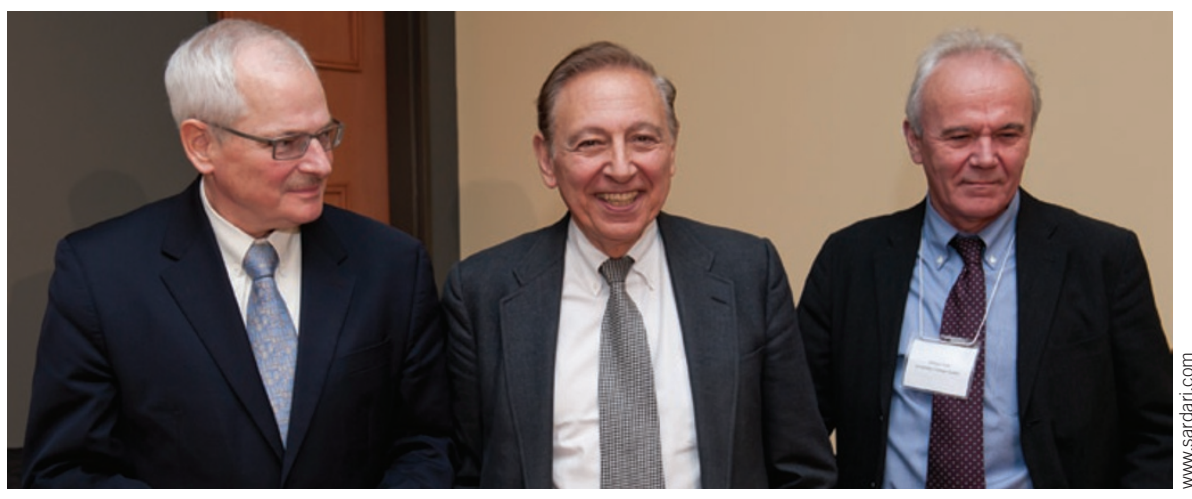

First responders: Global Virus Network co-founders Reinhard Kurth (left), Robert Gallo (center) and William Hall (right).

agencies such as the World Health Organization (WHO) and the US Centers for Disease Control and Prevention (CDC). Both of these agencies, which have ongoing discussions with GVN officials about how the groups can best work together, are also involved in controlling viral pathogens but are often more constrained by political considerations and region-specific funding support.

"We're not saying that the WHO or CDC can't do this. But because of our totally scientific approach, maybe we can get to it quicker," says GVN cofounder William Hall, a medical microbiologist at University College Dublin.

In addition to providing first-responder scientific know how, the network also plans to launch education initiatives to train more researchers about how to counter emerging infectious diseases. "We have to cultivate and nurture a younger generation of virologists with a keen motivation to deal with public health issues," says Jonathan Gershoni, a molecular immunologist at Tel Aviv University and the Israeli representative to the GVN.

Nathan Wolfe, a Stanford University virologist who directs the Global Viral Forecasting Initiative, a San Francisco-based infectious disease outbreak research and advocacy organization, welcomes the arrival of another group with a similar mandate. "What's being done now is just a drop in the bucket of what needs to be done in order to stop pandemics before they occur," he says.

Adam Mann

\section{UK plans $30 \%$ funding bump for translational research}

LONDON - The push for translational medicine got a boost in the UK last month when the government announced that it would devote $£ 775$ million ( $\$ 1.2$ billion) over five years for translational research focusing on high-priority disease areas such as cancer, heart disease and dementia. This funding cycle represents a $30 \%$ increase on the first round of such grants, which began in 2007.

"It's not a massive amount of money, but it's a realignment of priorities," says Chris Torrance, chief executive of the translational genomics company Horizon Discovery based in Cambridge, UK. "In a period where other people are taking cuts, it's significant," he adds.

The funds will be made available from April 2012 through the UK National Institute for Health Research, the research arm of country's National Health Service (NHS). The National Institute for Health Research currently has a dozen Biomedical Research Centres (BRCs) and 16 Biomedical Research Units (BRUs) in leading NHS and university partnerships.

Future funding is not restricted to existing BRCs and BRUs already in place at universities and hospitals. "It is entirely possible that new partnerships may arise as a result of this funding," according to James Hotson, a spokesperson for the UK Department of Health. "All NHS providers in England in collaboration with their university partner are eligible to apply."

Jonathan Weber, deputy principal of the Faculty of Medicine at Imperial College London, says that the government is wise to continue doling out funding for translational work through the BRCs. Past funding through this channel "has allowed us to develop new facilities for experimental medicine and train clinical researchers," Weber told Nature Medicine. "It has also enabled us to give project support to new drugs, devices and diagnostics arising out of our basic science laboratories, moving these products into clinical investigation in patients."

Torrance, whose company aims to facilitate the development of personalized medicine in the form of cell lines that, for example, model cancer genotypes, explains that translation is not only needed by patients but also creates an area of opportunity around which the UK can build a sustainable high-tech economy. "There's so much information now that needs to be translated," he says.

Bea Perks 